\title{
AUDITORÍA AMBIENTAL PARA IMPLEMENTAR UN SISTEMA DE GESTIÓN ISO 14001 EN LA PLANTA DE LÁCTEOS DE LA CENTRAL AGRARIA DE PRODUCCIÓN CHICHAUSIRI, JUNÍN ${ }^{\mathbf{4 6}}$.
} Fernando Suca Apaza ${ }^{47}$, Ide Gelmore Unchupaico Payano. ${ }^{48}$

Facultad de Ingeniería y Ciencias Humanas de la Universidad Nacional del Centro del Perú

\begin{abstract}
RESUMEN
La presente investigación tuvo como objetivo evaluar la factibilidad de implementar un sistema de gestión ambiental ISO 14001, determinar los grados de significancia de los impactos ambientales ocasionados e identificar sus medidas de control en una planta de quesos en Junín. Se utilizó la norma ISO 14001: 2004. El método consistió en dos etapas: primero se hizo una revisión de documentos relacionados al proceso productivo y, la segunda, consistió en efectuar dos visitas para entrevistar y encuestar a los responsables de la organización y la disposición de los ambientes internos y externos de la planta, finalmente, observar el proceso productivo de elaboración de quesos y entrevistas a los responsables de la planta. Los resultados muestran que en la recolección de leche utilizan materiales plásticos para sellar los porongos inoxidables generando residuos por el desgaste de los mismos lo que contamina el suelo en grado significativo, durante la pasteurización la fuente de calor es generada principalmente por la combustión de "champas" (pedazo de enredaderas esponjosas de los pastos que crecen en el suelo) provocando un aumento de la contaminación del aire en un grado de significancia media, también en esta etapa se identificó desperdicios de residuos de leche del orden del $3 \%$. Durante el enfriamiento se generan efluentes líquidos de agua mayores a $35^{\circ} \mathrm{C}$ provocando una disminución de dicho recurso de modo significativo, en el desuerado un $20 \%$ del suero es destinado a la alimentación de porcinos y el restante es desechado hacia los riachuelos que desembocan al lago. En el empacado existen residuos de plástico y telas contaminando el suelo de manera significativa. Dichos aspectos ambientales deben ser subsanados por medio de medidas de prevención y mitigación como: establecer un programa de mantenimiento preventivo para el sistema de agua, mejorar el sistema de transporte de efluentes, mejorar la contención durante la operación de llenado de moldes, minimización de residuos plásticos, utilizar telas de algodón y realizar una revisión para la mejora de las características del horno artesanal para optimizar el flujo de la llama. Se concluye que los impactos ambientales identificados tienen un efecto significativo en más de la mitad, si bien se identificó una medida de control del impacto ambiental referido al suero de la leche, ésta requiere ser optimizada, por tales razones no existen condiciones factibles para la implementación del SGA ISO 14001.
\end{abstract}

Palabras clave: Leche, queso, impactos ambientales, contaminación.

\section{AUDIT TO IMPLEMENT AN ENVIRONMENTAL MANAGEMENT SYSTEM ISO 14001 IN DAIRY PLANT OF AGRICULTURAL PRODUCTION CENTRAL chichausiri, Junín.}

\begin{abstract}
The present investigation was to evaluate the feasibility of implementing an environmental management system ISO 14001, to determine the degree of significance of the environmental impacts and identify control measures in a cheese plant in Junín. We used the ISO 14001: 2004. The method consisted of two stages: first was a review of documents related to the production process and the second, was to make two visits to interview and survey those responsible for the organization and layout of internal and external environments of the plant, finally, observe the production process of cheese making and interview with plant managers. The results show that the milk collection use plastic to seal the stainless porongos waste generated by wear thereof which contaminates the soil in significant degree, during pasteurization heat source is generated mainly by the burning of "huts "(piece of spongy grass vines growing on the ground), causing increased air pollution in a significant media degree, at this stage also identified waste milk residue around $3 \%$. During cooling water effluents generated above $35^{\circ} \mathrm{C}$ causing a decrease in that action so significant, draining $20 \%$ of serum is intended to feed pigs and the rest is discarded into streams that flow into the lake. In the packaging there is plastic waste and clothe contaminating soil significantly. These environmental aspects must be corrected through prevention and mitigation measures such as establishing a preventive maintenance program for water system, improve the transport system effluents, improve the containment during the mold filling operation, waste minimization plastics, cotton fabric used to make a review to improve the characteristics of the furnace scale to optimize the flow of the flame. It was concluded that the identified environmental impacts have a significant effect in more than a half, while a control measure identified environmental impact referred to whey, it needs to be optimized, for those reasons there are no conditions to implementation ISO 14001 EMS.
\end{abstract}

Key words: Milk, cheese, environmental impacts, pollution.

\footnotetext{
${ }^{46}$ Trabajo de investigación fue recibido el 07/05/2010 retornado para su revisión el 15/06/2010 y aprobado para su publicación 16/11/2010

${ }^{47}$ M.Sc. Ingeniero Agroindustrial. Facultad de Ingeniería y Ciencias Humanas, Universidad Nacional del Centro del Perú.

${ }^{48} \mathrm{Dr}$. Ingeniero Zootecnista. Facultad de Ingeniería y Ciencias Humanas, Universidad Nacional del Centro del Perú.
} 


\section{INTRODUCCIÓN}

El sector lácteo desarrollado a partir del ganado vacuno, tiene tradicional importancia en la producción agroindustrial en el país, presentando diferentes niveles de industrialización, desde los más tecnificados e industriales bajo economías de escala hasta los niveles más reducidos de autoconsumo. En ese rango existen en las zonas alto andinas organizaciones conformadas por la población rural quienes desarrollan las actividades de industrialización de la leche, en diferentes niveles de transformación y es el caso de la provincia de Junín, lugar donde la leche es comercializada en estado fresco, transformado en queso, mantequilla, yogurt y comercializado en los mercados cercanos. Principalmente el queso es uno de los productos que se producen en una mayor cantidad en dos presentaciones: queso fresco y prensado.

Por otro lado Junín también presenta una característica en cuanto se refiere a la contaminación, y precisamente el Lago Chinchaycocha es una superficie de agua donde desembocan por medio de los riachuelos, desechos, restos de las actividades agroindustriales y los provenientes de la actividad minera, afectando de sobremanera el ecosistema existente. Entonces cabe preguntarnos ¿Tendrá relación el efecto de los residuos de la actividad quesera con la contaminación de dicho medio ambiente? Afirmamos que debe ser así, porque el suero es un elemento con compuestos bioquímicos como por ejemplo la lactoalbúmina y lactoglobulina que demandan mucho oxígeno, provocando un proceso de eutrofización. Ello inevitablemente genera una reducción del contenido de dicho oxígeno disuelto, reduciendo las posibilidades de supervivencia de la fauna existente dentro del lago.

Por tales razones se ha planteado realizar la presente investigación en una unidad agroindustrial productora de quesos, a fin de evaluar la posibilidad de implementar un sistema de gestión ambiental que permita identificar dichos aspectos ambientales. Objetivo general: evaluar la factibilidad de implementar un sistema de gestión ambiental ISO 14001 en la planta de lácteos de la Central Agraria de Producción San Francisco de Chichausiri ubicado en la provincia de Junín y como objetivos específicos: determinar los grados de significancia de impactos ambientales ocasionados por el proceso de elaboración de queso fresco e identificar las medidas de control de los impactos ambientales ocasionados.

\section{MATERIALES Y MÉTODOS}

La presente Investigación se realizó en la Central Agraria de Producción San Francisco de Chichausiri ubicado sobre los 4105 m.s.n.m. en la Provincia y Región de Junín.
Se utilizó encuestas, fuentes bibliográficas, registradora de imágenes digitales y el manual de la Norma ISO 14001: 2004 (Sistema de Gestión Ambiental) del cual se formularon cuestionarios.

El método consistió en dos etapas:

Primera etapa: Revisión bibliográfica. Se revisaron documentos relacionados al proceso productivo de la leche de vaca en general.

Segunda etapa: Auditoría. Se realizaron dos visitas a la planta, para efectuar entrevistas con el Presidente de la organización, se observó la disposición de los ambientes (externos e internos) y equipos; durante la segunda visita se observó el proceso productivo y se continuó con la entrevista a sus integrantes.

\section{RESULTADOS}

Se ha identificado el flujo grama de procesamiento de quesos con los aspectos ambientales en cada etapa, como se puede apreciar en el siguiente Gráfico 1.

\section{Gráfico 1. Identificación de aspectos ambientales Proceso general de elaboración de quesos.}

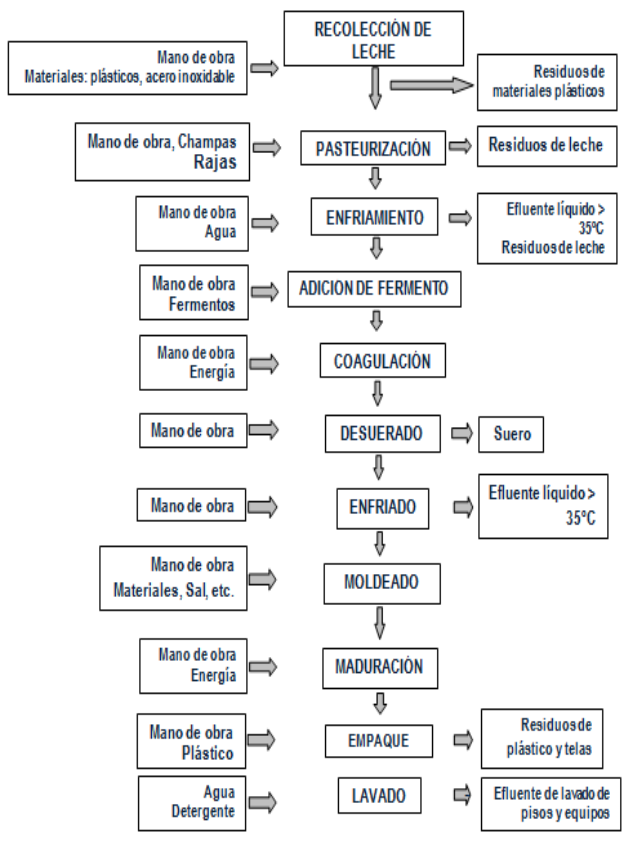

Fuente: Elaboración propia

El Gráfico 1 muestra en la primera etapa del proceso correspondiente a la etapa de recolección de la leche, la presencia de materiales plásticos con poca capacidad de biodegradación. En la etapa de pasteurización se ha podido identificar la utilización de abundante champa y rajas de 
eucalipto, por cuanto este proceso lo realizan de manera artesanal, generando emisiones de gases hacia el medio ambiente, pero también se pudo notar que dicho proceso no es óptimo debido a que genera un desperdicio de leche durante el llenado del mismo en el pasteurizador enchaquetado. Durante el empaque también se ve la presencia de desperdicios de plástico y telas. Con relación a los efluentes del suero, existen residuos en el enfriado, moldeado, maduración y lavado de pisos.

Los impactos ambientales identificados en el proceso general de la figura 1, fueron evaluados mediante los siguientes rangos de significancia: Valoración de impactos: (0) impacto nulo, (0.5) impacto medio y (1) impacto alto; y los rangos de significancia de impactos fueron: $(0-1.5)$ bajo (B), (2.0-3.0) medio (M) y (3.5 - 5.0) significativo (S).

Tabla 1. Evaluación de la Significancia de los Impactos Ambientales de la planta de quesos.

\begin{tabular}{|c|c|c|c|c|c|c|c|c|}
\hline \multirow{3}{*}{$\begin{array}{l}\text { ASPECTO } \\
\text { AMBIENTAL }\end{array}$} & \multicolumn{5}{|c|}{ Criterios de Significancia } & \multirow{3}{*}{ 롱 } & \multirow[b]{3}{*}{ 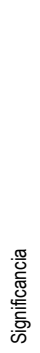 } & \multirow{3}{*}{$\begin{array}{l}\text { Impacto } \\
\text { Ambiental }\end{array}$} \\
\hline & & & & & & & & \\
\hline & 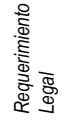 & $\begin{array}{l}\frac{\pi}{0} \\
\frac{0}{0} \\
\frac{0}{0} \\
\frac{d}{4}\end{array}$ & 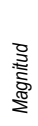 & 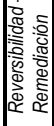 & 융 & & & \\
\hline \multicolumn{9}{|l|}{$\begin{array}{l}\text { PREPARADO DE } \\
\text { MATERIALES }\end{array}$} \\
\hline $\begin{array}{l}\quad \text { Residuos de } \\
\text { materiales } \\
\text { plásticos }\end{array}$ & Sí & & & & & & $S$ & $\begin{array}{l}\text { Contaminación del } \\
\text { suelo }\end{array}$ \\
\hline \multicolumn{9}{|l|}{$\begin{array}{l}\text { Consumo de } \\
\text { energía }\end{array}$} \\
\hline Mano de obra & No & 1 & 1 & 1 & 1 & 4 & S & $\begin{array}{l}\text { Mejora de aspecto } \\
\text { socio económico } \\
\text { de trabajadores }\end{array}$ \\
\hline \multicolumn{9}{|l|}{$\begin{array}{l}\text { PASTEURIZACIÓ } \\
N\end{array}$} \\
\hline $\begin{array}{l}\text { Consumo de } \\
\text { Champas y Rajas }\end{array}$ & No & 1 & 0.5 & 0.5 & 0.5 & $\begin{array}{l}2 . \\
5\end{array}$ & M & $\begin{array}{l}\text { Aumento de la } \\
\text { contaminación del } \\
\text { aire }\end{array}$ \\
\hline \multicolumn{9}{|l|}{ ENFRIAMIENTO } \\
\hline $\begin{array}{l}\text { Consumo de } \\
\text { agua para } \\
\text { enfriamiento }\end{array}$ & No & 1 & 1 & 1 & 0 & 3 & $S$ & $\begin{array}{l}\text { Disminución del } \\
\text { recurso }\end{array}$ \\
\hline $\begin{array}{c}\text { Generación de } \\
\text { efluentes líquidos }\end{array}$ & Sí & & & & & & $S$ & $\begin{array}{l}\text { Contaminación del } \\
\text { suelo }\end{array}$ \\
\hline \multicolumn{9}{|l|}{ COAGULACIÓN } \\
\hline Residuos de tela & Sí & & & & & & S & $\begin{array}{l}\text { Contaminación del } \\
\text { suelo }\end{array}$ \\
\hline DESUERADO & & & & & & & & \\
\hline
\end{tabular}

\begin{tabular}{|l|l|l|l|l|l|l|l|l|}
\hline $\begin{array}{l}\text { Generación de } \\
\text { suero y en } \\
\text { alimentación } \\
\text { porcinos. }\end{array}$ & No & 0.5 & 0.5 & 0.5 & 0 & $\begin{array}{l}1 . \\
5\end{array}$ & B & $\begin{array}{l}\text { Disminución de la } \\
\text { contaminación del } \\
\text { suelo. }\end{array}$ \\
\hline $\begin{array}{l}\text { MOLDEADO } \\
\text { (Efluentes, Molde) }\end{array}$ & No & 0.5 & 1 & 0.5 & 0 & 2 & $\mathrm{M}$ & $\begin{array}{l}\text { Contaminación del } \\
\text { suelo. }\end{array}$ \\
\hline MADURACIÓN & & & & & & & & \\
\hline EMPAQUE & & & & & & & & \\
\hline $\begin{array}{l}\text { Plásticos para } \\
\text { envase }\end{array}$ & Si & & & & & & $\mathrm{S}$ & $\begin{array}{l}\text { Contaminación del } \\
\text { suelo }\end{array}$ \\
\hline $\begin{array}{l}\text { LAVADO: ANTES, } \\
\text { DURANTEY } \\
\text { DESPUÉS DE LA } \\
\text { PRODUCCIÓN }\end{array}$ & & & & & & & & \\
\hline $\begin{array}{l}\text { Consumo de } \\
\text { agua }\end{array}$ & No & 1 & 0.5 & 0.5 & 1 & $\begin{array}{l}3 . \\
0\end{array}$ & $\mathrm{M}$ & $\begin{array}{l}\text { Disminución del } \\
\text { recurso }\end{array}$ \\
\hline
\end{tabular}

Fuente: Elaboración propia.

DISCUSIÓN

Los resultados de la evaluación de significancia de impactos ambientales muestran en mayor grado la significancia S, lo que nos indica que existe un impacto en el medio ambiente como producto de la elaboración de quesos en dicha planta, ocasionando contaminación del suelo, contaminación del aire y la disminución del recurso agua. Ello se puede ver en la tabla 1.

En consecuencia, los aspectos ambientales más relevantes identificados fueron: consumo de agua del río Añaspuquio, Generación de efluentes hacia el río Yarupuquio que desemboca en el lago Chinchaycocha, generación de residuos sólidos. Con relación a los impactos ambientales, el uso excesivo de agua contribuye a la disminución del recurso, asimismo un incremento del medio receptor. Con relación a los efluentes provenientes del lavado de las instalaciones como baldes de ordeño, porongos $y$ recipientes contamina el medio receptor. En el moldeado se ve la presencia de residuos sólidos y líquidos lo que contamina también el medio receptor. En la limpieza antes de la producción, se generan efluentes de agua corriente por lavado, durante la producción hay la presencia de efluentes con detergentes por lavado de marmita, utensilios plásticos y pisos. En el sellado de porongos se generan restos de plástico y telas sintéticas que son utilizados para sellar contaminando el suelo e incrementando los costos de producción. Durante el pasteurizado el diseño del horno quemador de la marmita es inapropiado, la llama sobresale del recipiente; además se pudo ver una producción excesiva de humo luego del encendido de la marmita, lo que genera una disminución del recurso.

\section{CONCLUSIONES}

Los impactos ambientales identificados tienen un impacto significativo en más de la mitad, existe una medida de 
control del impacto ambiental relacionado al suero de la leche, sin embargo ésta requiere ser optimizada. La planta deberá establecer un programa de mantenimiento preventivo para el sistema de agua, mejorar el sistema de transporte de efluentes, mejorar la contención durante la operación de llenado de moldes, establecer programa de limpieza, recoger sólidos lácteos manualmente al seco, utilizar agua a presión y uso de detergentes amigables, minimización de residuos plásticos o reemplazarlos con telas de algodón. Todo ello debería ser subsanado a fin de que pueda contar con las condiciones factibles para la implementación del SGA 14001.

\section{REFERENCIAS BIBLIOGRÁFICAS}

- Decreto Supremo No 008-2005 PCM. Ley Marco el Sistema Nacional de Gestión Ambiental. Lima, Perú. 2005.

- Espinoza, G. Gestión y Fundamentos de Evaluación de Impacto Ambiental. Banco Interamericano de Desarrollo BID - CED. Santiago de Chile. 2002.

- Pisúa G.L. Alnforme de Auditoría Ambiental, Microempresa Aldea Integral Pecuaria SRL. Alipe. Proyecto OEA: Programa Horizontal de Tecnologías Limpias y Energías Renovables. Lima Perú. 2006.

- Prando, R.R., Manual de Gestión de la Calidad Ambiental. Proyecto GTZ. Alemania. 1996.

- Reglamento (CEN) № 761/2001 del Parlamento Europeo y del Consejo de 19 de Marzo de 2001 por el que se permite que las organizaciones se adhieran con carácter voluntario a un sistema comunitario de gestión y auditoria medioambientales (EMAS).

- Sociedad Minera Cerro Verde S.A.A. Estudio de Impacto Ambiental "Proyecto de Sulfuros Primarios" Elaborado por Knight Piésold Consultores S.A. Lima. 2004.

- ISO: Sistema de Gestión Ambiental ISO 14001:2004 - Requisitos para su uso. 2008

- Aplicación de la ciencia y la tecnología para el fortalecimiento de micro, pequeña y mediana empresa (Mipimes) agroalimentaria en el sector rural de países de América Latina y del Caribe. 2008

- Caso SanCor Cooperativas Unidas limitada Argentina. 2008 